\title{
Long-term disease free survival [DFS] of stage IIIB malignant melanoma patient treated post-surgery with herbal treatment modalities
}

\author{
Sadanand Sardeshmukh, Sudha Gangal, Arvind Kulkarni, Vineeta Deshmukh*, Shweta Gujar, Sameer Gore, Renuka Gayal \\ Integrated Cancer Treatment and Research Centre [ICTRC], Wagholi, Pune, Maharashtra, India
}

\begin{abstract}
Objective: Long term survival of high-risk malignant melanoma is difficult to achieve in spite of radical surgery, adjunct chemotherapy, radiotherapy and biological therapy. The aim of this case presentation is to demonstrate effectiveness of herbal combination in achieving long term DFS of a high-risk melanoma patient.

Case presentation: We reports here a case of a patient with Stage IIIB malignant melanoma with palpable axillary lymph node. After surgical removal of only the primary lesion he did not opt for radiotherapy or chemotherapy or interferon therapy. Instead, he opted to take combination of herbal medicines at ICTRC, Pune. After the initial period of Ayurvedic treatment for 5 months, the palpable axillary lymph node enlarged. It was subjected to second surgery. The histopathological report of partial second surgery revealed residual melanoma with extensive exudate consisting of lymphocytes and histiocytes indicative of intense immune reactivity. No further recurrence or metastasis is noted for $20 \mathrm{yrs}$. The patient is continued to take herbal medicines and detoxifying Ayurvedic treatment modality called Panchakarma and is in Disease Free State with good quality of life and fit physical condition.
\end{abstract}

Conclusion: In this case improvement in immune status and quality of life is achieved using herbal medicines and Panchakarma treatment in absence of known anti-cancer treatments. Further clinical studies on large cohort and at the level of basic research are warranted.

\section{Introduction}

Malignant melanoma is considered as the most lethal skin cancer if not detected and treated at its early stage [1]. Irrespective of the size of primary tumour, very often this growth rapidly metastasizes and spreads not only in skin but also in draining lymph nodes and in more aggressive cases in other organs. Despite many surgical, chemotherapeutic and biological options for the treatment of melanoma, complete response rate has been poor [2].

Spontaneous regression of primary lesion of melanoma has often been reported [3-6]. However, the metastasis lesions grew faster in such cases and long-term disease-free survival has not been reported in high grade melanomas. It has been reported that the spontaneous regressing lesions were often associated primarily with intense immune reactivity which however did not have systemic effect.

We report here a case of a patient with Stage IIIB malignant melanoma. Although primary lesion was excised a small palpable axillary lymph node was visible three months post-surgery. He was advised radiotherapy / chemotherapy and interferon therapy; however, he opted for Ayurvedic herbal medicines and Panchakarma treatment. The herbs chosen for treatment were effective on various skin diseases and known to have immunomodulatory and anti-inflammatory effects [7-12]. He was also treated with a well-known Ayurvedic detoxifying treatment modality of Panchakarma [13-19]. The patient continued this treatment for last 20 years and is in fit physical condition without further appearance of the disease.

\section{Case report}

In June 1996, a 44 years old male patient [SJJ] of German ethnicity, residing in Germany, having familial association with other discordant cancers and having of various addictions was detected to have a mole of size $5 \mathrm{~mm} \times 9 \mathrm{~mm}$ in subscapular region. The lesion increased to the size of $1 \mathrm{~cm} \mathrm{x} 1 \mathrm{~cm}$ by June 1998 . The lesion was associated with itching and burning sensation. He reported to a clinic in Germany, where he was advised surgical excision of local tumour and was operated on $5^{\text {th }}$ June 1998.

The histopathology of excised tumour showed presence of malignant melanoma. It confirmed presence of nodular Superficially Spreading Melanoma [SSM] type with Breslow thickness of $2.04 \mathrm{~mm}$ and Clark level IV. The outer borders were free of tumour.

In September 1998; within three months after surgery, a lymph node in left axillary region was palpable. SJJ reported to the surgeon from the Clinic at Giessen. With the history of histopathology of primary tumour and with palpable lymph node in left axilla, he was advised

*Correspondence to: Vineeta Deshmukh, Integrated Cancer Treatment and Research Centre, Wagholi, Pune - 412207, Maharashtra, India, E-mail: ictrcpune@gmail.com

Key words: Melanoma, Herbal medicines, long term survival

Received: March 13, 2019; Accepted: March 22, 2019; Published: March 27, 2019 
wide excision surgery at the primary site and removal of palpable left axillary lymph node, followed by radiation and chemotherapy to prevent further metastasis. SJJ was also cautioned about poor prognosis of disease but at that point he was reluctant to undergo further surgery and allied conventional therapy.

SJJ opted to come to India and visited Ayurved Hospital and Research Centre [AHRC], Wagholi, Pune, Maharashtra, India where he consulted Dr S. P. Sardeshmukh in September 1998. He decided to take Ayurvedic treatment for his melanoma in preference to known modern medicines including biologicals. He was prescribed oral Ayurvedic herbal products along with Panchakarma treatment and was cautioned about the growth of metastatic lymph node which might need further surgical intervention.

The palpable left axillary node of SJJ remained stable for 4-5 months after commencement of Ayurvedic treatment till January 1999 and then increased in size which later turns out to an intense immune reactivity and inflammatory response as shown by surgical and histopathology report. In January 1999 he was advised to undergo surgery which was postponed by him for six months. During this period he felt acute pain in left chest wall which extended to left lateral thoracic wall, also radiating into left arm with restricted left hand movement. Patient had to take pain killers [Tab Tramadol] 3 hourly. CT scan of thorax did not show distant metastasis in lung. Abdominal sonography also indicated normal structure of liver, spleen and kidneys. Gall bladder and para-aortic space was without abnormality. Routine laboratory examinations including total blood cell count, blood biochemistry, urine analysis as well as serum levels of lactate dehydrogenase [LDH] showed no abnormality. He was advised by surgeon for immediate removal of the lymph node followed by radiotherapy.

SJJ was operated for axillary node in Germany on 21 June 1999. According to the operative notes the tumour was attached to the upper skin. The surgeons approached the surgery from ventral side to save bundle of nerves and blood vessels. As soon as they opened the left axillary lymph node for surgery, a large flow of exudate consisting of thick fluid and pieces of tissue drained out. Because of the complexity, instead of complete excision only tumour reduction was done. The histopathological report showed necrotic metastasis of low pigmented differentiated malignant melanoma. The epidermis was intact and showed lymphohistiocytic infiltrate and chronic inflammation. The soft tissue excision portion showed extensive necrosis of gigantic tumour cells with atypical mitosis. Besides, in the peripheral area, the accompanying infiltrate consisted of lymphocytes and hystiocytes.

According to AJCC staging of cutaneous melanoma $8^{\text {th }}$ edition, SJJ belongs to stage IIIB, with high risk of recurrence, The patient was advised to take radiotherapy and interferon therapy. He however declined the therapy and instead continued Ayurvedic treatment at AHRC, Pune. He underwent regular Panchakarma sittings for five times during 1998-2012 along with oral Ayurvedic medicines. He was under continued yearly surveillance with his physician in Germany, who found stable disease free condition and was advised to continue alternative Ayurvedic medicines. In his visit report of August 2016, his $17^{\text {th }}$ Melanoma treatment year, he was in good health without indication of residual disease. The physician, in routine physical check-up found no palpable lymph nodes, liver or spleen. He advised X-Ray thorax and abdominal sonography, both were without any abnormal findings. All clinical blood biochemistry including heamogram, liver function tests, renal function tests and markers like LDH and Protein S 100 were within normal range. Recent biochemistry parameters like heamogram, CRP done on $25^{\text {th }}$ September 2018 are also in normal range. His physician remarked as such extended healthy life for high risk melanoma patient without conventional treatment as 'phenomenal results'.

The patient is disease free today with no local or distant metastasis and enjoys absolutely normal quality of life. He continues with his business. The status of his disease, for the last twenty years, is depicted in a chart (Figure 1).

\section{Discussion}

Malignant melanoma is a serious disease with bad prognosis, commonly encountered in European countries. Incidence of Malignant melanoma is less than $5 \%$ among all skin cancers, but it is responsible for around $95 \%$ of skin cancer deaths. The annual incidence has increased dramatically over the past few decades [20]. Additional risk factor in this patient was history of various addictions including alcohol, smoking, snuffing.

In present case, a male patient SJJ, having history of cancer in family had primary malignant melanoma lesion on subscapular region. As per recent studies association of melanoma with familial discordant cancers is considered as a risk factor for melanoma [21]. Apparently

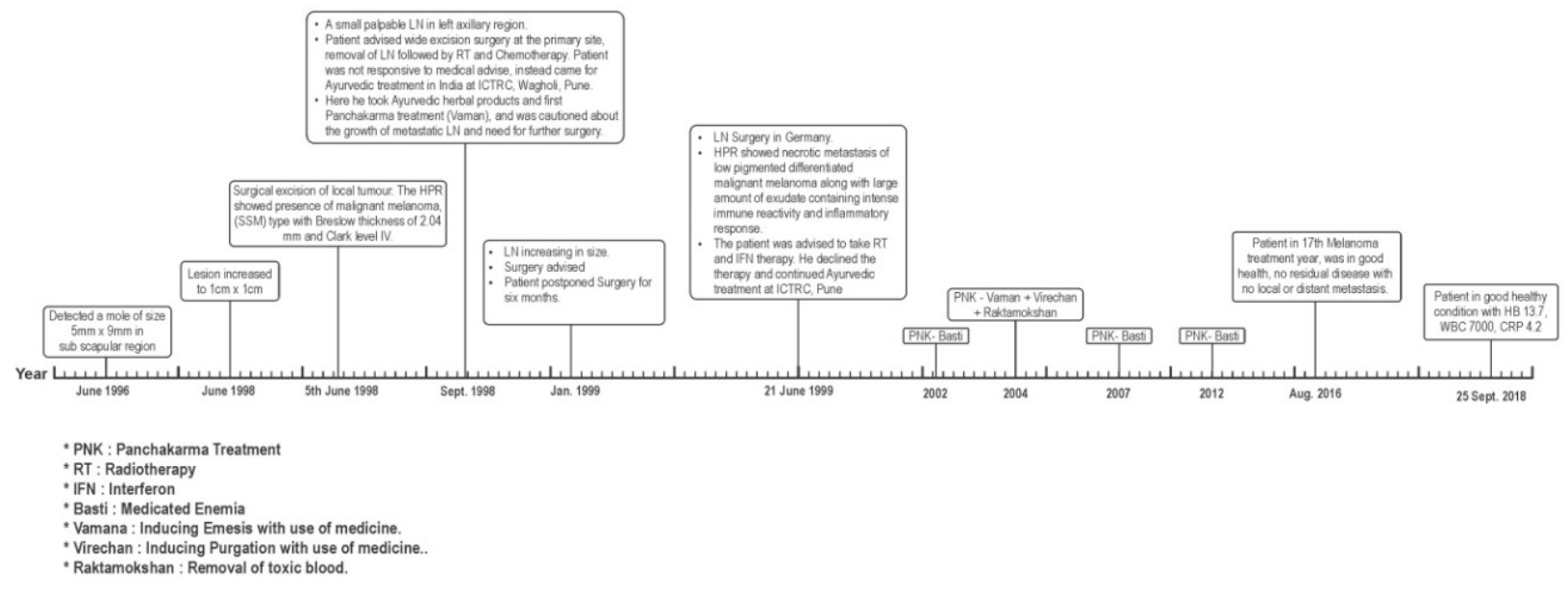

Figure 1. Status of disease for the last twenty years 
trunk malignant melanoma has a significantly higher risk of metastasis than limb melanoma [22].

In this case the malignant melanoma was of stage IIIB. Stage of melanoma depends upon how deeply the cancer is invaded into the skin, on involvement of metastatic lymph nodes and also on distant metastasis. The Breslow scale and the Clark scale are used to describe the depth of invasion. The Breslow scale measures vertical infiltration of tumour deep in dermis and across basal layer giving consideration to ulceration or inflammation in the skin area. It is advised that if the thickness of primary lesion is between $1 \mathrm{~mm}$ to $2 \mathrm{~mm}$, SLN biopsy is mandatory. In the present case the Breslow thickness was $2.04 \mathrm{~mm}$, indicative of possibility of draining lymph node involvement. Since the lymph node involvement was detected, the risk for recurrence and mortality was considered to be very high [23]. The Clark level refers the anatomic plane of invasion. Level IV of invasion detected in this patient indicates invasion into reticular dermis, which is also suggestive of low five year survival rate [59.35\%] in spite of conventional treatment [24].

In the present case, after surgical removal of primary, within three months, a lymph node in left axillary region was palpable which was removed after 9 months. The pathological report of excised lymph node showed its metastatic nature. No distant metastasis was detected. Therefore, these features indicate that, the TNM classification of the tumour is T3a N1a M0, suggestive of stage IIIB of malignant melanoma as per $8^{\text {th }}$ edition of AJCC guidelines [25].

Treatment options for this stage of melanoma are surgery, local radiotherapy to primary site and or chemotherapy and biological therapy consisting of interferon therapy and monoclonal antibodies [2].

In case of SJJ, the primary lesion was surgically removed. In spite of presence of Clark level IV of primary disease status, where in SLN biopsy is advocated. Such examination has not been reported. After three months of surgery a palpable lymph node in left axillary region was noted. The patient was advised wide excision of the primary site and excision of palpable lymph node for which he was reluctant. At this stage he took 1 sitting of Panchakarma and immediately started with oral Ayurvedic medicines. For the next three to four months the status of axillary lymph node did not change, which then started increasing rapidly. Upon surgical resection of affected lymph node it was evident that the lymph node had residual malignant melanocytes with lots of exudate and infiltrating lymphocytes and histiocytes with intense inflammation characteristic of immune reactivity. Unfortunately because the patient was from Germany and the incidence occurred years ago, we could not lay hands on either tissue or exudate to precisely identify the nature of infiltrating cells by immunocytochemistry. In following years local recurrence was not evident neither involvement of additional lymph nodes nor distant metastasis was seen. These data suggest that perhaps immune mechanism could have controlled further growth of malignant cells.

The herbal medicines were carefully chosen from the Ayurveda literature, which were used to treat the skin diseases as well as diseases akin to cancer, for treating this patient. These medicines are given in the dose of $500 \mathrm{mg}$ per day in the form of tablets. The combination consists of Amalaki [Emblica officinalis], Ananta [Decalepis hamiltonii], Triphala \{powder of fruits of Haritaki [Terminalia chebula], Amalaki [Emblica officinalis], Bibhitaki [Terminalia belerica]\}, Kumari [Aloe vera], Shatavari [Asparagus racemosus] and Haridra [Curcuma longa] for oral consumption. All these medicines are known to improve immune response, reduce inflammation and also exert cytotoxic effect on cancer cells [7-12].
Amalaki is described in Ayurvedic texts as Rasayan having immunomodulatory action. It also detoxifies blood [7]. On the other hand Ananta is reported to have anti-inflammatory activity in addition to detoxifying property especially in skin diseases [8]. Triphala is considered having best activity amongst all Rasayan and has potent activity in removing toxins especially from skin [9]. Amongst all the different activities of aloe vera, being Rasayan, it is immunomodulatory and beneficial in skin related anomalies. In addition it is known to detoxify spleen and liver [10]. Shatavari, as per Ayurvedic texts has dual activity being anti-inflammatory and effective in blood purification. It also possesses Rasayan i.e. immunomodulatory activity [11]. Haridra [curcumin] is the most popular herbal drug having multifarious activity used in today's medicine. According to Ayurvedic texts it has anti-inflammatory properties, and is effective in skin diseases and blood purification [12].

It is interesting to note that modern medicine is now geared to establish use of herbal preparations in medicine as research activity. The above mentioned drugs have also been subjected to analyse using modern biotechnology. Amalaki and Haritaki extracts have shown anti proliferative activity in vitro against cancer cell lines including mouse melanoma cell line [26,27]. Extracts of Ananta inhibits tumor progression and metastasis in vivo [28]. Extracts of components of Triphala together have shown in vitro cytotoxicity on cancer cell lines and have also shown regression of xenografts of human tumours [29]. Kumari is shown to have anti-cancer and immunomodulatory activity on melanoma cell lines [30]. Curcumin [Haridra] has been effective in multiple cellular and molecular events including alteration in cell cycles, induction of apoptosis, interference with activity of growth factors; protein kinase; transcription factors and key molecules involved in invasion; angiogenesis and metastasis in melanoma indicating its therapeutic effect [31]. Shatavari has also shown to have in vivo and in vitro cytotoxic activity against cancer cells [32].

The above reports show that herbal extracts of these medicines do show therapeutic effect in cancer using modern methodology.

Additional Ayurvedic treatment procedure used in this case is Panchakarma [13]. Panchakarma consists of 5 procedures which, according to Ayurvedic concept help in detoxifying the toxicities produced in tissues due to disease conditions. The five procedures are Vamana [inducing emesis with use of medicines], Virechana [inducing purgation with the use of medicines], Basti [medicated enema], Nasya [nasal instillation of medicines] and Raktamokshana [Removal of toxic blood]. For treatment any of these procedures alone or in combination are used at the discretion of the expert physician. These procedures are accompanied by oil-based treatment modalities and sudation. The most important associated procedures are strict diet and lifestyle practices.

This patient received all 5 Panchakarma modalities in five sittings during 1998 to 2012. As observed in significant number of cancer patients treated with Panchakarma treatment in our hospital, in initial curtail period of their cancer diagnosis, this patient also showed significant improvement in Quality of life and remarkable increase in Disease Free Survival (DFS) period. Mode of action and efficacy of Panchakarma treatment is well documented in scientific literature.

Panchakarma procedures are also receiving attention of modern medicine in treatment and research in many diseases including cancer. Panchakarma has been shown to induce modulation of metabotypes on healthy donors. Panchakarma promoted statistically significant changes in plasma levels of phosphatidylcholines, sphingomyelins and others in just 6 days [14]. Improvement in the quality of life has been shown in 
patients with skin disorders undergoing Panchakarma treatment [15]. Encouraging results are reported in patients with depression, anxiety; sleep disorders, hypertension, Parkinson's and Alzheimer's disease [16]. A detail study on intervention with Panchakarma procedure Basti- in obese individuals have documented that this procedure has modulated the immune response by regulating pro inflammatory cytokines, immunoglobulins and functional properties of $\mathrm{T}$ cells. These changes are associated with loss of weight, which is maintained even after 3 months after treatment [17]. Panchakarma treatment has been used in heart failure reversal in chronic heart failure patients with low ejection factor. The patients were followed for 90 days after Panchakarma treatment, and showed significant improvement in MAC [Maximum Aerobic Capacity] levels. This treatment thus can be used as a maintenance therapy in CHF patients with low ejection fraction [18]. In another study effect of Basti has been investigated on the pharmacokinetics using animal model. The study showed that phytochemicals of Basti formulations do get absorb in systemic circulation [19]. In present situation SJJ has so far received 5 sittings of different combinations of Panchakarma procedures during 1998 to 2012 with clinical improvement in quality of life.

As per the American Cancer Society reports, with all kinds of combined treatment modalities like intense immunotherapy in terms of interferon therapy or biological therapy with monoclonal antibodies, five-year survival rate for stage IIIB melanoma ranges from 40 to $78 \%$, The 10-year survival rate ranges from 24 to $68 \%$ [33]. No information on survival status for further period is available. In the present case the patient did not opt for any additional adjunct cancer therapy and preferred to undertake only Ayurvedic modalities of treatment. This patient belongs to high grade, high risk category with limited survival possibility. SJJ is however enjoying good quality of life for last 20 years with no evidence of disease. This favourable outcome may be associated with regular oral Ayurvedic medicinal treatment and Panchakarma.

\section{Conclusion}

From the published literature on malignant melanoma, it is evident, treatment procedures improving immune reactivity of patients are important in extending life span along with adjunct chemotherapy / radiotherapy. In this case we have tried to achieve improvement in immune reactivity using herbal medicines and Panchakarma in absence of above mentioned adjunct treatment. However this is a case report on a single patient and unless used on several cancer patients cannot be ascertained as a replacement for accepted anti-cancer treatment modalities. Such studies are in the pipeline in our hospital with additional collection of data.

\section{Informed consent}

The patient has given his consent for publication of this report.

\section{Conflict of interest}

The authors have no conflicts of interest.

\section{Acknowledgement}

The authors wish to acknowledge the help of Ayurvedic physicians and Panchakarma Vaidya of ICTRC, Wagholi, Pune in the treatment and follow up of patient.

\section{References}

1. Das P, Deshmukh N, Badore N, Ghulaxe C, Patel P (2016) A Review Article on Melanoma. J Pharm Sci Res 8: 112-117.
2. Domingues B, Lopes JM, et al. (2018) Melanoma treatment in review. Immunotargets Ther 7: 35-49. [Crossref]

3. Khosravi H, Andressa L, Akabane AL, Alloo A, Nazarian RM, et al. (2016) Metastatic melanoma with spontaneous complete regression of a thick primary lesion. JAAD Case Rep 2: 439-441.

4. Kalialis LV, Drzewiecki KT, Klyver H (2009) Spontaneous regression of metastasis from melanoma: review of the literature. Melanoma Res 19: 275-282.

5. Tarazona R, Duran E, Solana R (2015) Natural Killer Cell Recognition of Melanoma New Clues for a More Effective Immunotherapy. Front Immunol 6: 649.

6. Salman T (2016) Spontaneous tumor regression. Journal of Oncological Science 2: 1-4

7. Bhavaprakash Nighantu of Shri Bhavamishra, commented by Dr. K.C. Chunekar and edited by Dr. G.S. Pandey, Choukhmaba Bharati Academy,Varanasi, Reprint 2004, Shloka 39: 10.

8. Bhavaprakash Nighantu of Shri Bhavamishra, commented by Dr. K.C. Chunekar and edited by Dr. G.S. Pandey, Choukhmaba Bharati Academy,Varanasi, Reprint 2004, Shloka 238: 426.

9. Bhavaprakash Nighantu of Shri Bhavamishra, commented by Dr. K.C. Chunekar and edited by Dr. G.S. Pandey, Choukhmaba Bharati Academy,Varanasi, Reprint 2004, Shloka no 43: 12 .

10. Bhavaprakash Nighantu of Shri Bhavamishra, commented by Dr. K.C. Chunekar and edited by Dr. G.S. Pandey, Choukhmaba Bharati Academy,Varanasi, Reprint 2004 Shloka 229-230: 419.

11. Bhavaprakash Nighantu of Shri Bhavamishra, commented by Dr. K.C. Chunekar and edited by Dr. G.S. Pandey, Choukhmaba Bharatim Academy,Varanasi, Reprint 2004, Shloka 186-187: 392.

12. Bhavaprakash Nighantu of Shri Bhavamishra, commented by Dr. K.C. Chunekar and edited by Dr. G.S. Pandey, Choukhmaba Bharati Academy, Varanasi, Reprint 2004, Shloka 196: 114.

13. Charak Samhita by Agnivesha with Ayurveda Deepika commentary by Chakrapani Datta, edited by Vaidya Yadavji Trikamji Acharya, Chaukambha Prakashan, Varanasi, Siddhi Sthana, Chapter 1, Shloka 38: 683.

14. Peterson CT, Lucas J, St. John-Williams L, Thompson JW, Moseley MA, et al (2016) Identification of Altered Metabolomic Profiles Following a Panchakarmabased Ayurvedic Intervention in Healthy Subjects: The Self-Directed Biological Transformation Initiative [SBTI]. Scientific Reports 6: 32609.

15. Deshpande H, Shivakumar, Kavita MB, Tripathy TB, Chaturvedi A (2016) Assessment of Quality of Life in Patients with Skin Disorders Undergoing Ayurvedic Panchakarma as Management. J Evid Based Complementary Altern Med. 21: 215-220.

16. Sharma H, Chandola HM, Singh G, Basisht G (2007) Utilization of Ayurveda in health care: an approach for prevention, health promotion, and treatment of disease. Part 2-Ayurveda in primary healthcare. J Altern Complement Med 13: 1135-1150.

17. Thatte U, Chiplunkar S, Bhalerao S, Kulkarni A, Ghungralkar R, et al. (2015) Immunological \& metabolic responses to a therapeutic course of Basti in obesity. Indian J Med Res 142: 53-62.

18. Rohit S, Rahul M (2018) Efficacy of heart failure reversal treatment followed by 90 days follow up in chronic heart failure patients with low ejection fraction. $J$ Ayurveda Integr Med S0975-9476: 30024.

19. Auti SS, Ashok BK, Thakar AB, ShuklaVJ, Ravishankar B (2011) An experimenta study to evaluate the pharmacokinetic aspect of Lekhana Basti. Emaciating/ Desiccating Medicated Enema. AncSci Life 31: 38-43.

20. Tas B, Pilanci O, Koy Y, Tetikkurt U (2015) Nodular Melanoma-Like Superficial Spreading Melanoma Arising from Intradermal Unna Nevus-Can Incomplete Oncogenic-senescence be Responsible for Non-hierarchical Melanomagenesis? Pigmentary Disorders 2-5.

21. Frank C, Sundquist J, Hemminki A, Hemminki K (2017) Risk of other Cancers in Families with Melanoma: Novel Familial Links. Scientific Reports 7: 42601.

22. Voinea S, Blidaru A, Panaitescu E, Sandru A (2016) Impact of gender and primary tumor location on outcome of patients with cutaneous melanoma. J Med Life 9: 444448. [Crossref]

23. Mays MP, Martin RC, Burton A, Ginter B, Edwards MJ, et al. (2010) Should all patients with melanoma between 1 and $2 \mathrm{~mm}$ Breslow thickness undergo sentinel lymph node biopsy? Cancer 116: 1535-1544. 
24. Kelly JW, Sagebiel RW, Clyman S, Blois MS (1985) Thin level IV malignant melanoma. A subset in which level is the major prognostic indicator. Ann Surg 202: 98-103.

25. Gershenwald JE, Scolyer RA (2018) Melanoma Staging: American Joint Committee on Cancer [AJCC] 8th Edition and Beyond. Annals of surgical oncology 25: 2105-2110.

26. ZhangY, NagaoT, TanakaT, Yang C, Okabe H, et al. (2004) Antiproliferative Activity of the Main Constituents from Phyllanthusemblica. Biol Pharm Bull 27: 251-255.

27. Saleem A, Husheem M, Härkönen P, Pihlaja K (2002) Inhibition of cancer cell growth by crude extract and the phenolics of Terminalia chebula retz. fruit. $J$ Ethnopharmacol 81: 327-336. [Crossref]

28. Shathish K, Guruvayoorappan C (2014) Decalepishamiltonii inhibits tumor progression and metastasis by regulating the inflammatory mediators and nuclear factor ?B subunits. Integr Cancer Ther 13: 141-151.
29. Baliga MS (2010) Triphala, Ayurvedic formulation for treating and preventing cancer: a review. J Altern Complement Med 16: 1301-1308.

30. Tabolacci C, Cordella M, Turcano L, Rossi S, Lentini A, et al. (2015) Aloe-emodin exerts a potent anticancer and immunomodulatory activity on BRAF-mutated human melanoma cells. Eur J Pharmacol 762: 283-292.

31. Anand P, Sundaram C, Jhurani S, Kunnumakkara AB, Aggarwal BB (2008) Curcumin and cancer: an "old-age" disease with an "age-old" solution. Cancer Lett 267: 133-164. [Crossref]

32. Mitra SK, Prakash NS, Sundaram R (2012) Shatavarins [containing Shatavarin IV] with anticancer activity from the roots of Asparagus racemosus. Indian J Pharmacol 44: 732-736.

33. Roth E, Nall R (2016) Managing Stage 3 Melanoma. Health line newsletter.

Copyright: (02019 Sardeshmukh S. This is an open-access article distributed under the terms of the Creative Commons Attribution License, which permits unrestricted use, distribution, and reproduction in any medium, provided the original author and source are credited. 